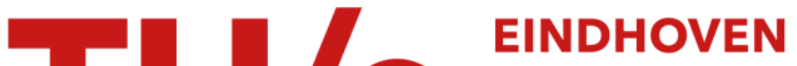 UNIVERSITY OF TECHNOLOGY
}

\section{Assessment of demand-response-driven load pattern elasticity using a combined approach for smart households}

\section{Citation for published version (APA):}

Paterakis, N. G., Tascikaraoglu, A., Erdinç, O., Bakirtzis, A. G., \& Catalaõ, J. P. S. (2016). Assessment of demand-response-driven load pattern elasticity using a combined approach for smart households. IEEE Transactions on Industrial Informatics, 12(4), 1529-1539. [7500042]. https://doi.org/10.1109/TII.2016.2585122

\section{Document license:}

TAVERNE

DOI:

10.1109/TII.2016.2585122

Document status and date:

Published: 01/08/2016

\section{Document Version:}

Publisher's PDF, also known as Version of Record (includes final page, issue and volume numbers)

\section{Please check the document version of this publication:}

- A submitted manuscript is the version of the article upon submission and before peer-review. There can be important differences between the submitted version and the official published version of record. People interested in the research are advised to contact the author for the final version of the publication, or visit the $\mathrm{DOI}$ to the publisher's website.

- The final author version and the galley proof are versions of the publication after peer review.

- The final published version features the final layout of the paper including the volume, issue and page numbers.

Link to publication

\section{General rights}

Copyright and moral rights for the publications made accessible in the public portal are retained by the authors and/or other copyright owners and it is a condition of accessing publications that users recognise and abide by the legal requirements associated with these rights.

- Users may download and print one copy of any publication from the public portal for the purpose of private study or research.

- You may not further distribute the material or use it for any profit-making activity or commercial gain

- You may freely distribute the URL identifying the publication in the public portal.

If the publication is distributed under the terms of Article 25fa of the Dutch Copyright Act, indicated by the "Taverne" license above, please follow below link for the End User Agreement:

www.tue.nl/taverne

Take down policy

If you believe that this document breaches copyright please contact us at:

openaccess@tue.nl

providing details and we will investigate your claim. 


\title{
Assessment of Demand-Response-Driven Load Pattern Elasticity Using a Combined Approach for Smart Households
}

\author{
Nikolaos G. Paterakis, Member, IEEE, Akın Taşcıkaraoğlu, Member, IEEE, \\ Ozan Erdinç, Senior Member, IEEE, Anastasios G. Bakirtzis, Fellow, IEEE, \\ and João P. S. Catalão, Senior Member, IEEE
}

\begin{abstract}
The recent interest in the smart grid vision and the technological advancement in the communication and control infrastructure enable several smart applications at different levels of the power grid structure, while specific importance is given to the demand side. As a result, changes in load patterns due to demand response (DR) activities at end-user premises, such as smart households, constitute a vital point to take into account both in system planning and operation phases. In this study, the impact of price-based DR strategies on smart household load pattern variations is assessed. The household load datasets are acquired using model of a smart household performing optimal appliance scheduling considering an hourly varying price tariff scheme. Then, an approach based on artificial neural networks (ANN) and wavelet transform (WT) is employed for the forecasting of the response of residential loads to different price signals. From the literature perspective, the contribution of this study is the consideration of the DR effect on load pattern forecasting, being a useful tool for market participants such as aggregators in pool-based market structures, or for
\end{abstract}

Manuscript received October 30, 2014; revised February 20, 2016 and April 25, 2016; accepted June 11, 2016. Date of publication June 27, 2016; date of current version August 04, 2016. This work was supported by FEDER funds through COMPETE and by Portuguese funds through FCT, under FCOMP-01-0124-FEDER020282 (Ref. PTDC/EEA-EEL/118519/2010), UID/CEC/50021/2013, and SFRH/BPD/103744/2014, by The Scientific and Technological Research Council of Turkey (TUBITAK) under Project Grant 115E215, and by the EU Seventh Framework Program FP7/2007-2013 under Grant 309048 (project SiNGULAR Paper no. TII-15-1690.R2. (Corresponding author: J. P. S. Catalão.)

N. G. Paterakis is with the Department of Electrical Engineering, Eindhoven University of Technology, Eindhoven 5600 MB, The Netherlands (e-mail: n.paterakis@tue.nl).

A. Taşcıkaraoğlu is with Yildiz Technical University, Istanbul 34220, Turkey (e-mail: atasci@yildiz.edu.tr).

O. Erdinç is with Yildiz Technical University, Istanbul 34220, Turkey, and also with the Instituto de Engenharia de Sistemas e Computadores, Investigação e Desenvolvimento em Lisboa, Instituto Superior Técnico, University of Lisbon, Lisbon 1049-001, Portugal (e-mail: oerdinc@yildiz.edu.tr).

A. G. Bakirtzis is with the Department of Electrical and Computer Engineering, Aristotle University of Thessaloniki, Thessaloniki 54124, Greece (e-mail: bakiana@eng.auth.gr).

J. P. S. Catalão is with the Instituto de Engenharia de Sistemas e Computadores, Tecnologia e Ciência, University of Porto, Porto 4200465, Portugal, with the C-MAST, University of Beira Interior, Covilhã 6201-001, Portugal, and also with the Instituto de Engenharia de Sistemas e Computadores, Investigação e Desenvolvimento em Lisboa, Instituto Superior Técnico, University of Lisbon, Lisbon 1049-001, Portugal (e-mail: catalao@ubi.pt).

Color versions of one or more of the figures in this paper are available online at http://ieeexplore.ieee.org.

Digital Object Identifier 10.1109/TII.2016.2585122 load serving entities to investigate potential change requirements in existing DR strategies, and effectively plan new ones.

Index Terms-Artificial neural networks (ANN), demand response (DR), electric vehicles (EV), home energy management, load forecasting, smart household, wavelet transform (WT).

\section{NOMENCLATURE}

The main nomenclature used throughout the paper is stated below. Other symbols and abbreviations are defined where they first appear.

\section{A. Indices}

$t$

\section{B. Parameters}

$A_{j} \quad$ Approximate series at level $j$.

$A E_{m} \quad$ Energy requirement of smart appliance $m[\mathrm{kWh}$.

$C E_{\mathrm{EV}} \quad$ Charging efficiency of the EV.

$C R_{\mathrm{EV}} \quad$ Charging rate of the $\mathrm{EV}$ [kW per time interval].

$D_{j} \quad$ Detail series at level $j$.

$D E_{\mathrm{EV}} \quad$ Discharging efficiency of the EV.

$\mathrm{DR}_{\mathrm{EV}} \quad$ Discharging rate of the $\mathrm{EV}[\mathrm{kW}$ per time interval].

$F_{m} \quad$ Period in which the operation of smart-appliance $m$ should be finished.

$N \quad$ Maximum power that can be drawn from the grid $P_{t}^{\text {other }} \quad$ Inelastic power demand of the household [kW]. $R P_{m} \quad$ Rated power of smart appliance $m[\mathrm{kWh}$.

$S_{m} \quad$ Period in which the operation of smart appliance $m$ should be started.

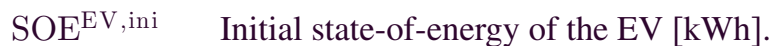

$\mathrm{SOE}^{\mathrm{EV}, \max }$ Maximum allowed state-of-energy of the EV [kWh].

$\mathrm{SOE}^{\mathrm{EV}, \mathrm{min}}$ Minimum allowed state-of-energy of the EV [kWh].

$T^{a} \quad$ Arrival time of the EV.

$T^{d} \quad$ Departure time of the EV.

$T_{m}^{\text {dur }} \quad$ Duration of operation of smart-appliance $m$.

$T^{f, c} \quad$ Period at which EV should be fully charged.

$T^{f, d} \quad$ Period at which EV should be fully discharged, if applicable.

$\Delta T \quad$ Time step duration [h]. 
$\lambda_{t}^{\text {buy }} \quad$ Price of energy bought from the grid

\section{Variables} [cents/kWh].

\begin{tabular}{|c|c|}
\hline$P_{m, t}^{A}$ & $\begin{array}{l}\text { Power of smart appliance } m \text { during period } t \\
{[\mathrm{~kW}] \text {. }}\end{array}$ \\
\hline$P_{t}^{\mathrm{EV}, \mathrm{ch}}$ & EV charging power $[\mathrm{kW}]$ \\
\hline$P_{t}^{\mathrm{EV}, \mathrm{dis}}$ & EV discharging power [kW]. \\
\hline$P_{t}^{\mathrm{EV}, \text { used }}$ & $\begin{array}{l}\text { Power used to satisfy household load from the } \\
\text { EV }[k W] \text {. }\end{array}$ \\
\hline$P_{t}^{\text {grid }}$ & Power supplied by the grid $[\mathrm{kW}]$ \\
\hline $\mathrm{SOE}_{t}^{\mathrm{EV}}$ & State-of-energy of the EV [kWh]. \\
\hline$u_{m, t}$ & $\begin{array}{l}\text { Binary variable }-1 \text { if smart appliance } m \text { is } \mathrm{ON} \\
\text { during period } t \text {, else } 0 \text {. }\end{array}$ \\
\hline$u_{t}^{\mathrm{EV}}$ & $\begin{array}{l}\text { Binary variable }-1 \text { if } E V \text { is charging during pe- } \\
\text { riod t, else } 0 .\end{array}$ \\
\hline$y_{m, t}$ & $\begin{array}{l}\text { Binary variable }-1 \text { if smart appliance } m \text { starts } \\
\text { during period } t \text {, else } 0 \text {. }\end{array}$ \\
\hline$z_{h, m, t}$ & $\begin{array}{l}\text { Binary variable }-1 \text { if smart appliance } m \text { stops } \\
\text { during period } t \text {, else } 0 \text {. }\end{array}$ \\
\hline
\end{tabular}

\section{INTRODUCTION}

\section{A. Motivation and Background}

$\mathbf{T}$ HERE is an increasing trend for smart grid applications in different parts of the world, also promoted by incentives given by the governments of leading countries. A central concept within the smart grid vision is to enable the active participation of demand-side resources instead of simply considering them as passive power consumers [1], [2]. In this respect, demand response (DR) strategies are adopted in order to induce effective changes in the load demand instead of only adapting the generation side to load changes [3], [4].

Residential end-users are responsible for a significant portion of electrical energy consumption, reaching up to 40\% [5], and therefore, residential DR strategies are given specific importance. Smart households may act in order to lower their electricity bills or can be directly controlled by load serving entities (LSEs) in order to mitigate demand peaks. For the purpose of enabling smart residential end-users premises, home energy management systems (HEMS) are employed to allow for the effective operation of such end-user points in coordination with LSEs under DR strategies [6]. HEMS receive relevant input information (such as pricing data that can be day-ahead, hour-ahead, peak power limits, and warnings for planned contingencies) from LSEs and schedule the operation of all electrical loads of the household with a predefined aim under imposed constraints by means of LSE restrictions and consumer preferences.

As regards the current state of HEMS adoption around the world, major differences can be noticed from region to region. The U.S. leads the adoption of HEMS. European utilities are also supporting relevant pilot projects [7]. Nevertheless, one may argue that since benefits for both the consumers and the utilities have already been recognized and because numerous major companies (including Siemens, Intel, etc.) have already rendered commercially available HEMS [8], their penetration rate in the near future is likely to increase.
Currently, the main barrier to the widespread adoption of such systems is their cost. However, in the longer term, the investment costs can be met by the benefits for the consumer. Typically, hourly prices are lower than flat rates. Furthermore, subsides and other incentives may be offered by utilities since shifting electricity eases the stress on the power distribution system (improving reliability, limiting ageing of equipment, etc.) [9]. Another crucial concern is the preservation of the comfort level of the end-users. However, several appliances (such as washing machines, dishwashers, and electric vehicles-EVs) can be operated in such a way that the demand is reduced during relatively high price periods without compromising the enduser's comfort. For such smart households and other end-users premises, price elasticity of the electrical demand is strongly related to real-time pricing, indicating the relative change in demand that would result from a change in the electricity price [10].

Modeling the reaction of a consumer to price variations through elasticity involves the determination of the so-called elasticity matrix that is created by analyzing the behavior of the consumer, as well as the possible facilities the consumer may own, such as energy storage systems, distributed generation, and EVs or the actual ability of shifting the power requirements [11]. This matrix-based consideration of elasticity is basically employed as a feedback term when used in electricity price adjustment procedure [11]. This process requires the exact knowledge of the elasticity coefficients, something that is not easily defined a priori. Especially for the smart household structure that can include several thermostatically and nonthermostatically controllable appliances with different characteristics, it can even be less efficient and may not be effective to provide elasticity matrices that would also need relevant updates. Thus, to overcome the necessity of exact knowledge of elasticity coefficients and the mentioned assumption-based comparison, load forecasting tools that will also consider price elasticity of the load variations can be developed, serving also as a tool for aggregators to provide a more effective planning of their actions in day-ahead markets.

\section{B. Literature Overview}

A broad literature has been dedicated to the implementation of various load forecasting strategies from different points of view. Borges et al. [12] employed an autoregressive (AR) model for the forecasting of individual substation loads and then aggregated the obtained forecasts with bottom-up and topdown methodologies. However, the detailed dynamics of different types of individual end-users (residential, industrial, and commercial) were not considered in [12], a fact that prevents the possibility of applying different pricing schemes to different end-user types due to their usage habits and the possibility to respond to DR strategies. Ozturk et al. [13] provided a twoside interactive DR operation and restructuring between utility and a residential end-user, in which the utility forecasts the behavior of residential load to restructure its pricing strategy in order to shave peaks in the original load pattern. However, the methodology in [13] is based on first forecasting the normal load pattern and then providing a DR strategy to reshape it. Byun et al. [14] employed a load forecasting strategy as a part 
of their smart energy distribution and management system to derive load patterns and update through end-user usage data, but neglected the direct impacts of imposed pricing schemes on load pattern variations. Chaouch [15] applied a methodology to forecast intraday household load pattern by using historical data based on usage habits, but has also neglected the use of pricing-load pattern data pairs that can be significantly useful for aggregators to determine the way in which end-users react to pricing schemes aiming to effectively schedule their shortand mid-term activities. Behnke et al. [16] utilized an artificial neural network (ANN)-based load forecasting model as a part of a smart microgrid energy management system. Nevertheless, they have only considered historical data-based forecasted load as a basis for considering the possible deviations caused by DR actions. Ghelardoni et al. [17] proposed a long-term energy load forecasting methodology that was presented as a useful tool for smart grid applications to better observe the load usage statistics. As a general informative study, Hernandez et al. [18] provided a detailed survey on load forecasting techniques.

These papers together with other studies not referred here have provided valuable contributions to the application of smart grid concepts through forecasting techniques. However, none of these studies has considered the load pattern forecasting of a residential end-user committed to price-based DR strategies aiming to investigate the impacts of different pricing signals on the expected end-user load. Indeed, this is a novel point of this study and the basis of a useful tool, especially for aggregators and system operators in order to achieve both economic and technical benefits.

As a supporting document describing why and how the lack of such price-elastic demand forecasting tools is affecting the loads and Independent System Operators (ISOs), [19] analyzed the California ISO market using real data. The analysis provided in [19] concluded that price spikes can occur in day-ahead and real-time markets for demand bids with high level of elasticity due to several factors. One major factor is that the accuracy of a load forecasting realized by an ISO can decrease due to not considering significant changes in demand induced by changes in prices. Thus, Kohansal and Mohsenian-Rad [19] recommended the development of load forecasting tools that also consider the impact of price elasticity on demand. This issue is also analyzed in [20] and [21]. In this study, price elasticity of demand is explicitly taken into account in the forecasting procedure. In this way, a tool apt to be used by the operators of systems offering extensive residential DR programs can be developed as suggested in [19]-[21].

\section{Contributions}

In this study, an HEMS model is used to construct price-load pairs which are applied to a hybrid wavelet transform (WT)ANN load forecasting approach. The contribution of this study is twofold.

1) The proposed study provides a direct mapping between input price patterns and output DR driven load patterns. This scheme will allow the LSEs to further improve their planning by changing the pricing scheme, or by imposing further limitations of peak power if the expected load pattern needs to be restricted.
2) There are two major problems in defining the price elasticity of a smart household that are bypassed by applying the proposed methodology: 1) the concept of price elasticity requires the knowledge of a set of "basis" or "expected" prices and consumption according to which the calculations should be performed; and 2) physical constraints such as the availability of the EV, user comfort preferences, etc., complicate the calculation of cross elasticity.

\section{Organization}

The remainder of this paper is organized as follows: Section II discusses the approaches targeting at forecasting the demand of an aggregated group of consumers or an individual consumer. Section III describes the MILP model of the HEMS and the WT-ANN forecasting approach for the load pattern elasticity assessment driven by DR. Section V describes the results obtained for different test cases. Finally, in Section VI, conclusion is drawn.

\section{Forecasting the LOAd of an Aggregation Versus a SINGLE CONSUMER}

Extensive literature has been devoted to the forecasting of load demand. Two main categories of studies may be identified in terms of the approach that is followed: either forecasting is performed considering an aggregation of consumers, or for an individual consumer, even at the level of a specific appliance. Regarding the first category, there has been a great deal of studies that assess the applicability of different approaches such as time series models, ANN, and Fuzzy Logic (FL) on load forecasting at distribution transformer, region, and country level. The adequate accuracy of these approaches is a result of the relatively regular behavior of an aggregation of a wide range of loads. On the contrary, a limited-yet increasing-number of studies with respect to individual consumer demand forecasting have been published so far, mainly due to two reasons: 1) lack of high-resolution data for these small-scale units; and, 2) dynamic and stochastic load profiles affected greatly by consumer habits and usage patterns, appliance specifications, seasonal changes, etc. The main difference between forecasting the load of a group of consumers and the load demand of a single end-user is that the former can be accurately predicted based mainly on historical data. Nevertheless, despite these differences and the complexity involved in forecasting individual load profiles, both points of view are areas of intense research.

\section{METHOdOLOGY}

\section{A. HEMS Model for Smart Household Operation}

The HEMS model that is employed in this study is a variant of the model that has been presented in [22]. First, the HEMS model is presented in order to explain how the training pairs required for the forecasting approach are obtained. The HEMS regulates the operation of the smart household considering prices and other signals from the LSE, load consumption of smart appliances, etc., together with different consumer preferences. It should be noted that for the sake of simplicity, the 
possibility of selling energy back to the grid is not considered in this study.

The objective is to minimize the total daily cost of electricity consumption. The price variables given in (1) are time dependent, a fact that implies time varying prices for bought energy, where the optimization variable is the total power bought from the grid at time $t\left(P_{t}^{\text {grid }}\right)$ :

$$
\text { Minimize } T C=\sum_{t} P_{t}^{\text {grid }} \cdot \Delta T \cdot \lambda_{t}^{\text {buy }} .
$$

The constraints presented hereafter comprise the basic body of the HEMS operation. Any time granularity can be used simply by selecting the appropriate $\Delta T$. For instance, for a 15-min interval $\Delta T=0.25 \mathrm{~h}$.

1) Power Balance: Equation (2) states that the total load consisting of the inelastic residential load $\left(P_{t}^{\text {other }}\right)$, the charging needs of the $\mathrm{EV}\left(P_{t}^{\mathrm{EV}, \mathrm{ch}}\right)$, and the smart appliances $\left(P_{m, t}^{A}\right)$ is either satisfied by the grid $\left(P_{t}^{\text {grid }}\right)$ or by the procurement of energy from the $\mathrm{EV}\left(P_{t}^{\mathrm{EV}}\right.$, used $)$ :

$$
P_{t}^{\text {grid }}+P_{t}^{\mathrm{EV}, \text { used }}=P_{t}^{\mathrm{other}}+P_{t}^{\mathrm{EV}, \mathrm{ch}}+\sum P_{m, t}^{A} \quad \forall t .
$$

2) EV Modeling: Equation (3) enforces the fact that the actual power provided by the EV discharge $\left(P_{t}^{\mathrm{EV} \text {,dis }} \cdot D E_{\mathrm{EV}}\right)$ is equal to the power to be used to cover a portion of the household needs $\left(P_{t}^{\mathrm{EV} \text {,used }}\right)$. Constraints (4) and (5) impose a limit on the charging $\left(P_{t}^{\mathrm{EV}, \mathrm{ch}}\right)$ and discharging $\left(P_{t}^{\mathrm{EV}, \text { dis }}\right)$ power of the EV. The idle state of the EV can be described by any of these constraints by the time the respective power variable is allowed to have zero value. Equations (6)-(10) describe the state-of-energy (SOE) of the EV. Constraint (6) forces the SOE at every interval $\left(\mathrm{SOE}_{t}^{\mathrm{EV}}\right)$ to have the value that it had at the previous interval $\left(\mathrm{SOE}_{t-1}^{\mathrm{EV}}\right)$, plus the actual amount of energy that is transferred to the EV battery if it is charging at that interval, minus the energy that is subtracted if the EV battery is discharging during that interval. At the arrival time of the EV to the household, the SOE of the EV coincides with the initial SOE of the EV $\left(\mathrm{SOE}^{\mathrm{EV}}\right.$,ini $)$, as described by (7). Constraint (8) limits the SOE of the EV battery to be less than its capacity $\left(\mathrm{SOE}^{\mathrm{EV}, \max }\right)$. Similarly, constraint (9) prevents the deep discharge of the EV battery by imposing a least $\mathrm{SOE}$ limit $\left(\mathrm{SOE}^{\mathrm{EV}, \mathrm{min}}\right)$. Equations (10) and (11) represent the option of having the EV battery fully charged or discharged at the least SOE at preselected time intervals. Finally, (12) ensures that all the variables related to EV modeling are zero apart from the time interval between arrival time of the EV to the household $\left(T^{a}\right)$ and departure time of the $\mathrm{EV}$ from the household $\left(T^{d}\right)$.

$$
\begin{aligned}
P_{t}^{\mathrm{EV}, \text { used }}= & P_{t}^{\mathrm{EV}, \mathrm{dis}} \cdot D E_{\mathrm{EV}} \quad \forall t \in\left[T^{a}, T^{d}\right] \\
P_{t}^{\mathrm{EV}, \mathrm{ch}} \leq & C R_{\mathrm{EV}} \cdot u_{t}^{\mathrm{EV}} \quad \forall t \in\left[T^{a}, T^{d}\right] \\
P_{t}^{\mathrm{EV}, \mathrm{dis}} \leq & \mathrm{DR}_{\mathrm{EV}} \cdot\left(1-u_{t}^{\mathrm{EV}}\right) \quad \forall t \in\left[T^{a}, T^{d}\right] \\
\mathrm{SOE}_{t}^{\mathrm{EV}}= & \mathrm{SOE}_{t-1}^{\mathrm{EV}}+C E_{\mathrm{EV}} \cdot P_{t}^{\mathrm{EV}, \mathrm{ch}} \Delta T-P_{t}^{\mathrm{EV}, \mathrm{dis}} \Delta T \\
& \forall t \in\left[T^{a}, T^{d}\right] \\
\mathrm{SOE}_{t}^{\mathrm{EV}}= & \mathrm{SOE}^{\mathrm{EV}, \text { ini }}, \quad \text { if } t=T^{a}
\end{aligned}
$$

$$
\begin{aligned}
& \mathrm{SOE}_{t}^{\mathrm{EV}} \leq \mathrm{SOE}^{\mathrm{EV}, \text { max }} \quad \forall t \in\left[T^{a}, T^{d}\right] \\
& \mathrm{SOE}_{t}^{\mathrm{EV}} \geq \mathrm{SOE}^{\mathrm{EV}, \text { min }} \quad \forall t \in\left[T^{a}, T^{d}\right] \\
& \mathrm{SOE}_{t}^{\mathrm{EV}}=\mathrm{SOE}^{\mathrm{EV}, \text { max }} \quad \forall t \geq T^{f, c} \in\left[T^{a}, T^{d}\right] \\
& \mathrm{SOE}_{t}^{\mathrm{EV}}=\mathrm{SOE}^{\mathrm{EV}, \text { min }}, \text { if } t=T^{f, d} \in\left[T^{a}, T^{d}\right] \\
& \mathrm{SOE}_{t}^{\mathrm{EV}}=P_{t}^{\mathrm{EV}, \mathrm{used}}=P_{t}^{\mathrm{EV}, \mathrm{dis}}=P_{t}^{\mathrm{EV}, \mathrm{ch}}=0 \\
& \forall t \notin\left[T^{a}, T^{d}\right] .
\end{aligned}
$$

3) Smart Appliances: In this paper, smart appliances are considered to be supplied with a fixed power for a specific amount of time. The total operation is considered flexible by means of shifting the time at which they start their operation. Constraints (13)-(19) hold only if the smart appliances participate in the coordination scheme; else, they are treated as inelastic load. The presented formulation can be easily extended to include also appliances that can interrupt their operation and continue at a later time.

$$
\begin{aligned}
\sum_{t=S_{m}}^{F_{m}} P_{m, t}^{A} & =A E_{m} \quad \forall t \\
P_{m, t}^{A} & =R P_{m} \cdot u_{m, t} \quad \forall t \\
y_{m, t} & =z_{m,\left(t+T_{m}^{\text {dur }}\right)} \quad \forall t \\
\sum_{t \in T} y_{m, t} & =1 \quad \forall t \\
\sum_{t \in T} z_{m, t} & =1 \quad \forall t \\
y_{m, t}+z_{m, t} & \leq 1 \quad \forall t \\
y_{m, t}-z_{m, t} & =u_{m, t}-u_{m,(t-1)} \quad \forall t .
\end{aligned}
$$

4) Power Transaction Restrictions: Equation (20) implements the logic of power exchange. $N$ is a positive integer value that imposes a limitation on the power that can be drawn from the grid. This limitation may represent a restriction imposed by the aggregator or the responsible entity for the end-user electrification in order to face the situation where in its control area exist multiple households that own HEMS. The implementation of a time-varying peak power drawn from the grid limit as a different DR strategy can be easily adapted on this formulation, by replacing the $N$ by a time-dependent parameter.

$$
P_{t}^{\text {grid }} \leq N \quad \forall t .
$$

Different consumer options and behavioral details can be expressed by fixing the charging and discharging variables of the EV to be zero in the appropriate time intervals.

\section{B. Forecasting Model}

1) Proposed Structure: The uncertainty in the generation and consumption values in power systems brings about severe problems in maintaining the reliability of system operations, such as frequency regulation and scheduling. In order to alleviate these impacts, forecasting systems are presented as the most realistic and cost-effective strategy among the other possible solutions. The efficiency of the forecasting systems depends 
mainly on the accuracy of the predictions. In the literature, particular interest has been demonstrated in addressing the challenging question of how to produce better forecasts required to maintaining the reliability of the system operations. Conventional statistical models have been widely used in the literature, but ANN-based approaches have dominated the studies in the last decades due to their capability of identifying the relation between the input and output data in time series. The main interest has recently been focused on advanced combined models, which exploit the unique advantages of single models in order to decrease the prediction error [23]. For this purpose, a combined forecasting model based on WT and ANN is employed in this study.

Most of the statistical forecasting methods presented in the literature have a similar structure in terms of their use of input data, i.e., 1) they use a large amount of historic data; and 2) they update the datasets with recent measurements. These approaches generally follow a recursive approach in the prediction process. The input dataset is completely updated once the real measurements are obtained. Then, the recursive process continues for another given time step. However, this method causes the final prediction error to increase gradually, aggregating the error value obtained at each step.

In contrast with the mentioned conventional methods used for updating the input dataset, a totally different approach that is based on "one-time training" is employed in this study. Thus, the time-consuming training stage repeated for each new data is avoided in the model. This feature is of great importance for the approaches including a data decomposition method, since these methods have a slow response to new data. Furthermore, to reduce the duration of the training stage, a data refinement process is implemented in this study. With this objective, all the available training data are applied to a data selection model that basically performs a partial correlation analysis between the test set and input set, and selects only the most informative data to be used in training stage. The mentioned process facilitates and speeds up the training phase considerably without causing any accuracy decrease in the test set.

In order for this tool to be practically adopted by an LSE, the required data should be readily accessible. The proposed approach requires the daily price and load variation during the training phase, while during the deployment phase only the daily price variations are required. Regarding the electricity prices, the day-ahead hourly varying prices are announced several hours before the beginning of the settlement day. An LSE or an aggregator is a market participant and as a result is de facto aware of the market prices.

Nowadays, in several markets there are entities that offer the opportunity to residential consumers to enroll to time-varying pricing programs. In current practice, there are two ways of pricing the consumer under such programs: 1) the end-user is aware the "previous" day of the day-ahead prices and is priced according to them, e.g., in MISO; and 2) the end-user is aware of the day-ahead prices but is priced based on the real-time prices that are not known a priori, e.g., in PJM. The proposed approach addresses the first case. Furthermore, because of the fact that these programs have been commercialized and aim

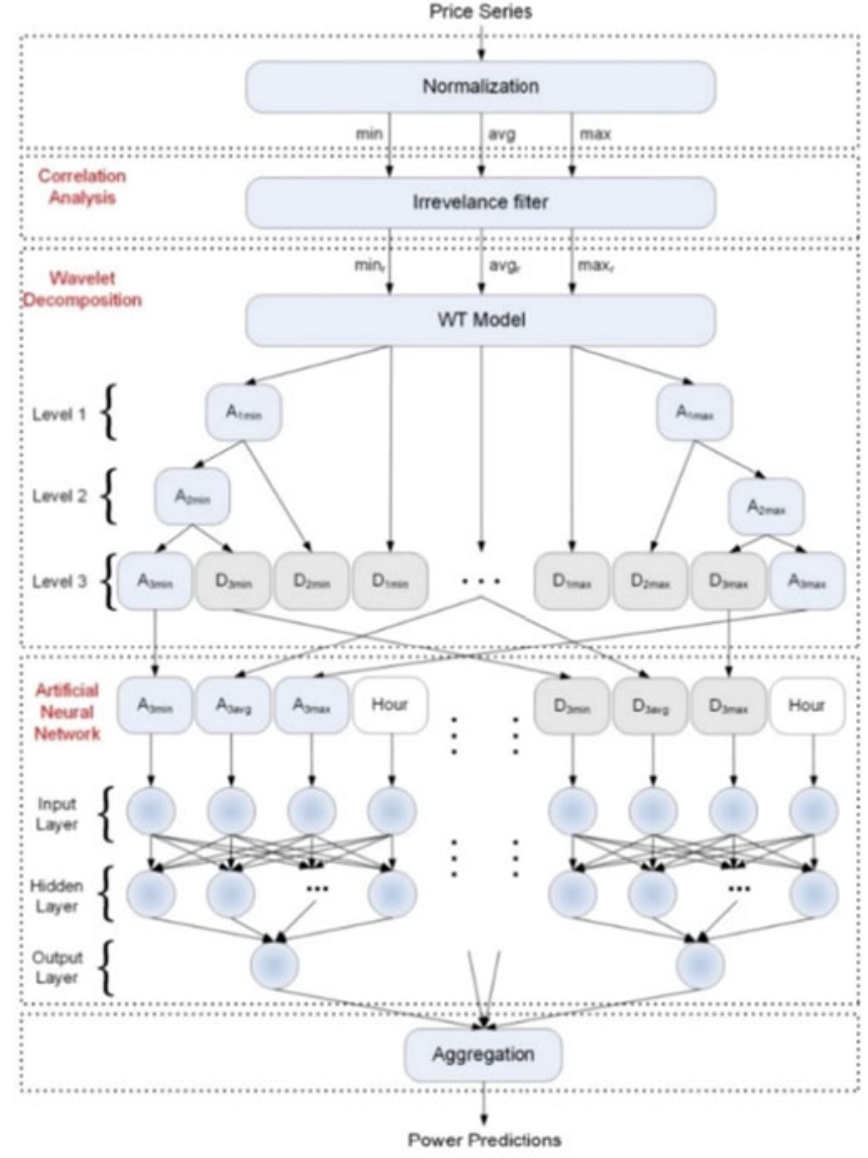

Fig. 1. Flowchart of the proposed DR-based load pattern forecasting strategy.

to stimulate end-user awareness, the relevant pricing data are easily accessible and as a result this study utilizes real pricing data. Practical evidence, i.e., the increasing adoption of smart meters, also suggests that aggregators will be able to access data concerning both prices (since they are market participants) and individual power consumption profiles directly through the advanced metering infrastructure installed at residential-end user premises. However, despite the availability of relevant enabling technologies, for a series of reasons that were previously discussed, the so-called "smart households" that employ automated decision making systems (HEMS) to control loads such as EVs and "smart" appliances are not yet popular [9]. As a result, relevant data are scarce. For this reason, the load profile for the residential consumer is generated employing the HEMS that was presented in Section III-A, assuming that the end-user is rational (i.e., aims to minimize the electricity procurement cost). Thus, it should be clearly stated that the HEMS model is not a key element of the proposed approach; it is a tool to provide the relevant training and testing pairs to analyze the proposed methodology.

The proposed power prediction model consists of four stages, as shown in Fig. 1. In the first stage, price values are normalized for the purpose of deriving time-independent values. The most relevant data are selected by a correlation analysis to increase prediction accuracy, as well as to decrease computational time. 
Afterward, WT is employed to decompose the power series into a number of more regular subseries in the training stage, the future values of which are separately forecasted using an ANN model. Finally, the predictions of the subseries are aggregated to reach the power forecasts of the original values.

It is rendered clear that the approaches including a decomposition method are more appropriate to reveal the relation between two datasets in comparison with the single prediction models. Another important point is that the decomposition process enables to predict each subset, i.e., approximation and detail levels, with a different configuration of an ANN model. In other words, the numbers of layers and neurons, type of activation functions, and size of training datasets can be determined separately with respect to the data and the results obtained in the training stage. The different stages are explained in the following sections.

2) Normalization: The input signal for the normalization stage is the daily 24-h price series in cents per kilowatthour. The normalization stage consists of three parallel operations that include normalization by division to minimum, average, and maximum values of the mentioned 24 -h daily price series. The main aim of the normalization is first to merge the prices of different days in the same logic as the HEMS structure mainly decides the household operation considering the value of the price of an hour relevant to other prices in different hours. For example, 4 cents/kWh can be the average value of a sample day, while the same value can be the maximum price in another day. Thus, the price series are considered directly without normalization, then the forecasting strategy will try to allocate the same output to these 4 cents/kWh input despite the fact that an HEMS would generally allocate more power in the case of being the average rather than the maximum price. The reason for normalizing by division to all minimum, average, and maximum is to further capture the position of the data considering all major aspects of a $24-\mathrm{h}$ data series. Therefore, three normalized time series are used as an input in the correlation analysis-based data selection stage.

3) Data Selection: The performance is generally proportional to the amount of training data in forecasting methods. However, a large set of ineffective data might cause a highly complex input-output mapping function in the training stage, which results in prediction of performance degradation and computational burden increase in the forecasting stage. Therefore, an input data selection method is used in this paper to filter out the irrelevant data before training. In order to determine the most informative inputs, a correlation analysis between the normalized price values for the target days and candidate price inputs in the training set is applied. When the correlation value of an input candidate day is greater than a certain threshold, which means that it has a more similar profile with the price values of the target day than most of the other candidates, the data of this day are considered as a relevant feature. Otherwise, these daily data are filtered out.

4) WT Model: Among the various data decomposition methods (WT, empirical model decomposition, blind source separation techniques, etc.), WT is considered to be the most widely accepted model for forecasting applications due to its ability of time-frequency analysis. WT decomposes time series into a set of subseries at different frequency levels, as displayed in Fig. 1. These subseries present a relatively more stationary behavior than the original series. These series can then be forecasted with a lower error. In this study, a three-level wavelet decomposition, which generates one approximation, $A_{3}$, and three detail components, $D_{1}, D_{2}$, and $D_{3}$ at the end, is used with Daubechies wavelet of order 4 by carrying out a detailed analysis on the effects of these parameters on the model performance.

5) ANN Model: In this paper, the future values of the subseries obtained by the means of WT are predicted with a multilayer feedforward back propagation (FFBP) network. Several tests on the training data are conducted to select the number of layers and neurons for each case. Finally, the total power prediction is calculated by aggregating the predicted values of the subseries. It should be noted that the periods of the day are also applied to the ANN models as an input in addition to the normalized and refined price values. High correlation between the power consumption values and time during a day helps to improve prediction performance.

\section{Benchmark Models}

In order to evaluate the accuracy of the realized predictions, three benchmark methods are also used in this study, namely, a linear model, an ANN model, and a combination of these two models. In the first model, a linear equation is obtained by relating normalized price values and power data in the training set, which is also the underlying idea of all conventional time series models such as AR and autoregressive moving average (ARMA). Price test data are then used to calculate target power values. The second model has been widely implemented in the literature of load forecasting providing reasonable accuracy. Among the different network types, a multilayer FFBP network is employed in the study because of its relatively simple structure. In order to improve the model performance, the network specifications such as the type of training algorithm, number of layers and hidden neurons, and type of transfer function are determined with a preliminary study in the training set. Briefly, a three-layer network, i.e., one input layer, one hidden layer and one output layer is adopted, and the number of input and output layers is chosen as that of input vector (i.e., four) and that of the next power forecast (i.e., one), respectively. Regarding the number of hidden layer neurons, an analysis is carried out considering model complexity and results obtained in the training stage, resulting in a different value for each model configuration.

It has been seen from the results of both benchmark models that linear model is more effective for the forecast of the periods in which the input-output mapping function exhibits a relatively more stable behavior. Similarly, the nonuniform periods are modeled with a higher precision using the ANN model. Based on these conclusions, the linear model and ANN model are combined by assigning a weight coefficient to each model for the hours of the day using (21):

$$
P(x)=\sum_{i=1}^{T} \beta_{i} p_{i}(x)
$$


TABLE I

HOUSEHOLd APPLIANCE DATA

\begin{tabular}{lclc}
\hline \hline Appliance & Power $[\mathrm{kW}]$ & \multicolumn{1}{c}{ Appliance } & Power $[\mathrm{kW}]$ \\
\hline Oven & 2.4 & TV & 0.083 \\
Cooker hood & 0.225 & Desktop computer & 0.15 \\
Microwave & 1.2 & Air conditioner & 1.14 \\
Refrigerator & 1.666 & Hair straightener & 0.055 \\
Iron & 2.4 & Printer & 0.011 \\
Toaster & 0.8 & Lighting & 0.1 \\
Kettle & 2 & Other (Fixed) & 0.05 \\
Hairdryer & 1.8 & Washing machine & 1.4 \\
Telephone & 0.005 & Dishwasher & 1.32 \\
\hline \hline
\end{tabular}

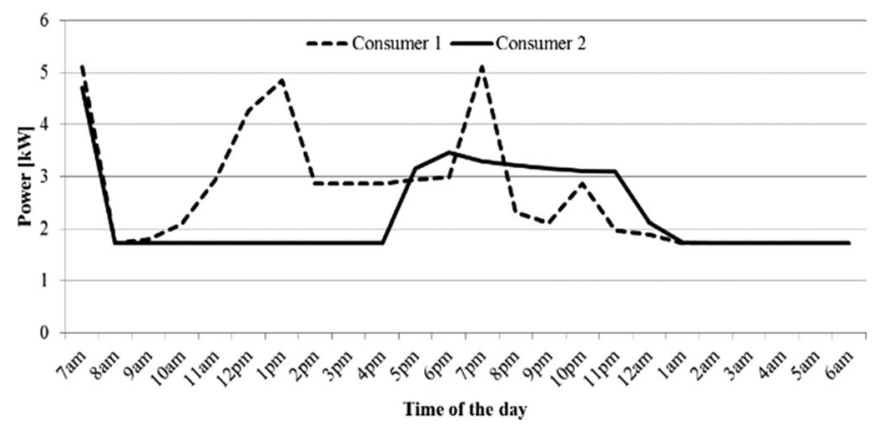

Fig. 2. Inflexible load variations for Consumer 1 and Consumer 2.

where $P(x)$ is the final prediction, $p_{i}(x)$ is an hourly prediction, and $\beta_{i}$ is the weight of $i$ th model, respectively.

In this study, a random set of days is chosen for the model training and weights are calculated using the minimum square error pseudoinverse technique, so that a coefficient is assigned to models depending on prior knowledge of prediction accuracy in the given period.

\section{Tests And Results}

To test the proposed methodology, the dynamic pricing-load demand training pairs are first obtained for the load forecasting strategy using an MILP model of HEMS coded in GAMS v.24.1.3 and the solver CPLEX v.12. The household load demand is provided considering power values of real household appliances obtained from [24]. The relevant appliance data are presented in Table I. It should be noted that the washing machine and the dishwasher are considered to be optimally operated by the HEMS based on user preferences.

Two types of consumers and two case studies for each of them are considered. The first type of consumer Consumer 1 represents a four-member family house where there is a nonworking person that consumes energy during the day. The second type of consumer Consumer 2 represents a single-person household that is working during the daytime. It should be noted that both types of consumers are assumed to possess an EV. The case studies for both consumers are divided according to the possibility of $\mathrm{V} 2 \mathrm{H}$ operation. The considered inflexible load variations for Consumer 1 and Consumer 2, apart from the washing machine, dishwasher and EV loads, are presented in Fig. 2. In order to obtain the mentioned price-load pattern pairs, 1096 days of pricing

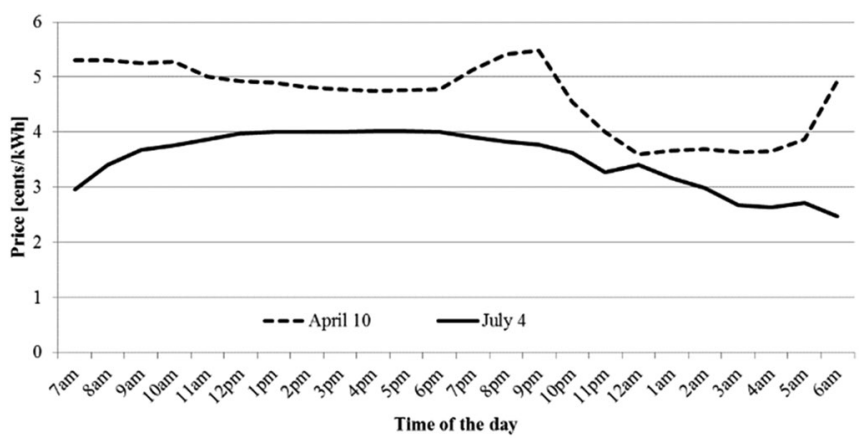

Fig. 3. Price variations for both randomly selected test days.

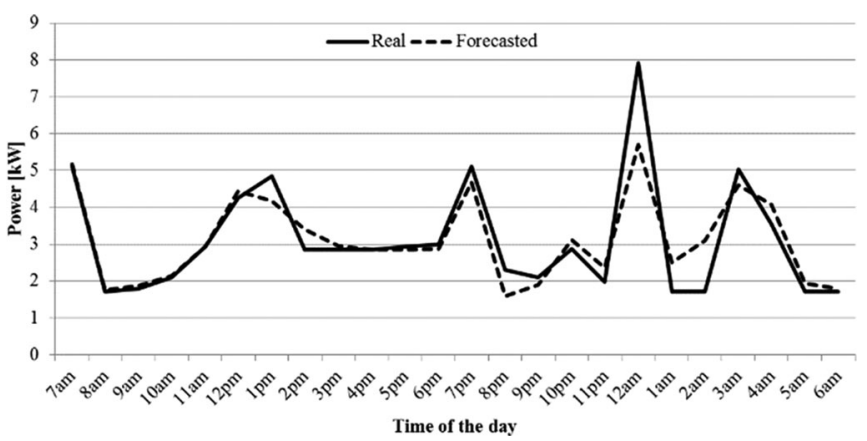

Fig. 4. Real and forecasted values (Consumer 1-Case 1, April 10, 2014).

data (starting from January 1, 2011) acquired from [25] are fed into the HEMS model and four cases are discerned:

1) Consumer 1-Case 1: Consumer 1 with EV just as a load.

2) Consumer 1-Case 2: Consumer 1 with EV capable of $\mathrm{V} 2 \mathrm{H}$.

3) Consumer 2-Case 1: Consumer 2 with EV just as a load.

4) Consumer 2-Case 2: Consumer 2 with EV capable of $\mathrm{V} 2 \mathrm{H}$.

For each case, 1096 price-load pattern pairs are used as training data for the proposed load forecasting strategy. The prediction model performance is tested under different conditions of randomly selected days and the relevant results are discussed below. The mentioned randomly selected days are April 10 and July 4 of 2014 and the relevant pricing data [25] that will be given as input to the trained combined load forecasting model is given in Fig. 3.

Initially, the normalized data are refined according to their information values. After the feature selection process, the decomposed series are extracted by the WT method. The WT method decomposes the power series that correspond to the price data determined, considering the relevant threshold, into four subsets. Then, the predictions of each subset are carried out with the proposed ANN structure for the different consumer types and cases. The results for the four different case studies during two different randomly selected test days are presented in Figs. 4-11. As seen, for each consumer, case and price variation, the WT-ANN strategy ensures quite reasonable results, capturing the main dynamics of DR driven load pattern, even extreme variations within the load shape. 


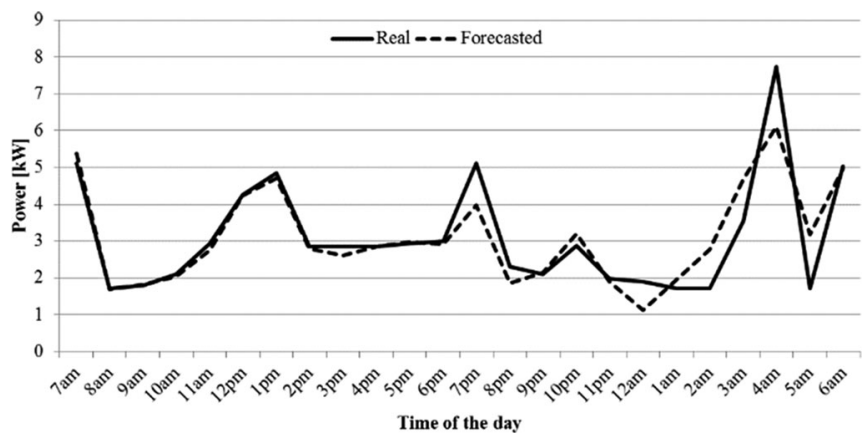

Fig. 5. Real and forecasted values (Consumer 1-Case 1, July 4, 2014).

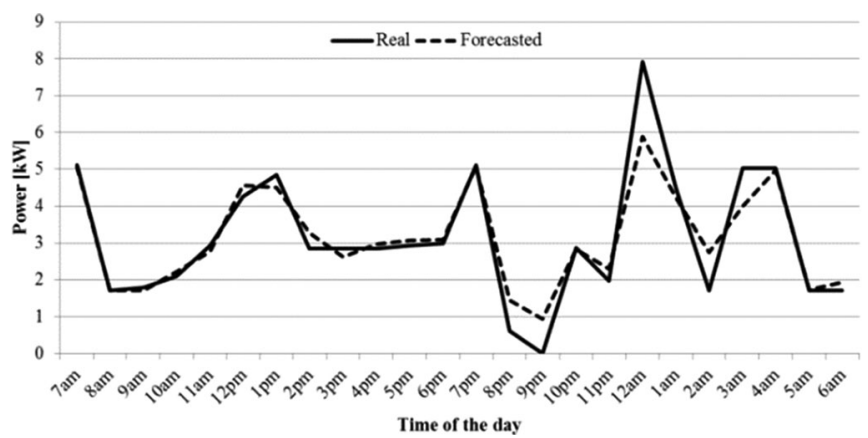

Fig. 6. Real and forecasted values (Consumer 1-Case 2, April 10, 2014).

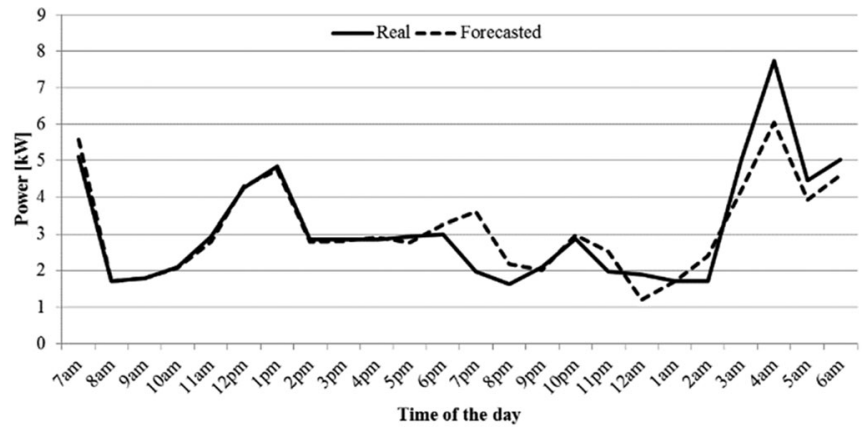

Fig. 7. Real and forecasted values (Consumer 1-Case 2, July 4, 2014).

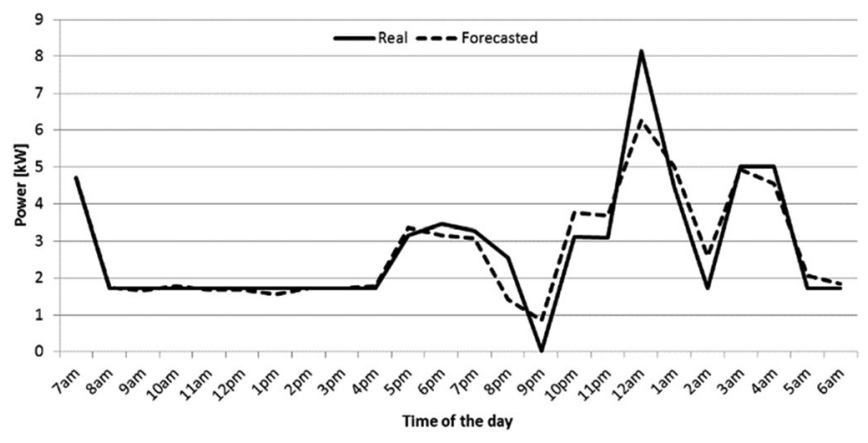

Fig. 8. Real and forecasted values (Consumer 2-Case 1, April 10, 2014).

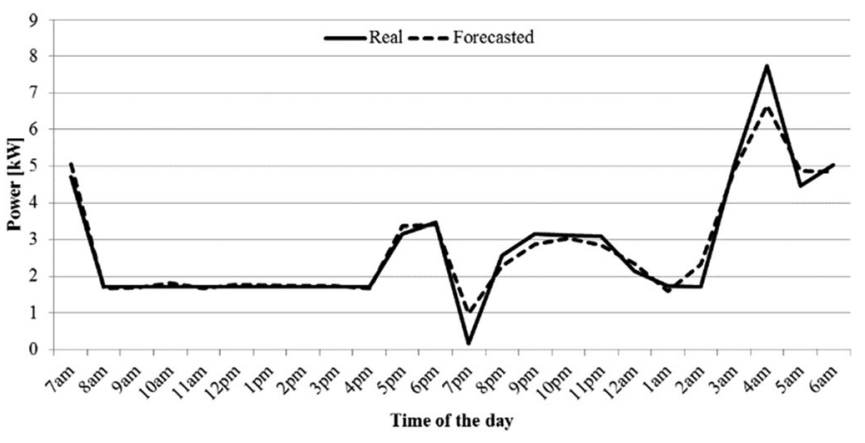

Fig. 9. Real and forecasted values (Consumer 2-Case 1, July 4, 2014).

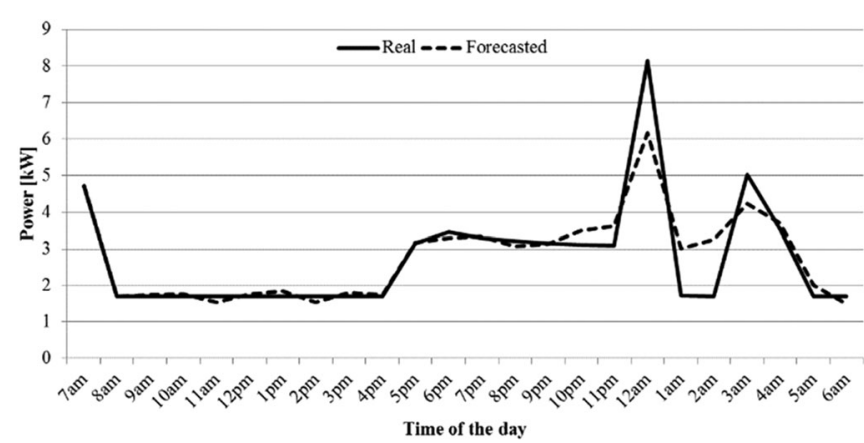

Fig. 10. Real and forecasted values (Consumer 2-Case 2, April 10, 2014).

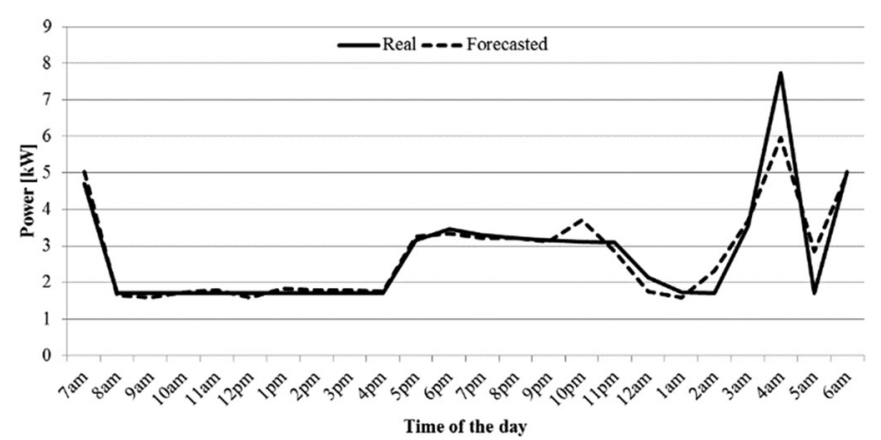

Fig. 11. Real and forecasted values (Consumer 2-Case 2, July 4, 2014).

In order to investigate how uncertainty associated with different parameters (e.g., charging requirement and maximum charging horizon of $\mathrm{EV}$ related to $\mathrm{EV}$ arrival time and initial SOE) affect the prediction results, six subcases are also provided for each case study and for every consumer type defined previously, as presented in Table II. It should be noted that, for the sake of simplicity, it is assumed that the departure time of the EV is 6 A.M. in all scenarios.

The associated mean absolute error (MAE) and root-meansquared error (RMSE) values are listed in Table III for the proposed and benchmark models and for all the cases related to each consumer type defined in this study. Note that the average of four error values (i.e., two consumers and two cases) is provided 
TABLE II

SubCASES TO INVESTIGATE THE EFFECTS OF UNCERTAINTY RELATED TO Different Model Parameters on Forecasting ACCuRACY

\begin{tabular}{lcc}
\hline \hline Subcase notation & EV arrival time & Initial SOE \\
\hline $\mathrm{a}$ & 10 P.M. & $8 \mathrm{kWh}$ \\
$\mathrm{b}$ & 5 P.M. & $8 \mathrm{kWh}$ \\
$\mathrm{c}$ & 3 P.M. & $8 \mathrm{kWh}$ \\
$\mathrm{d}$ & 10 P.M. & $5 \mathrm{kWh}$ \\
$\mathrm{e}$ & 5 P.M. & $5 \mathrm{kWh}$ \\
$\mathrm{f}$ & 3 P.M. & $5 \mathrm{kWh}$ \\
\hline \hline
\end{tabular}

for each day and each error metric in order to decrease data complexity. The MAE gives the mean deviation between the real and predicted data, while the RMSE is dominated by larger error terms due to the squares of differences. In addition to these negatively oriented error metrics, the normalized RMSE (NRMSE), which is the RMSE normalized by the range of real data, is computed to provide a scale-independent error metric. Here, it should be noted that "base" notation in Table III refers to the initial cases depicted in Figs. 4-11, while notations from "a" to " $\mathrm{f}$ " refer to the subcases defined in Table II. Besides, it should also be stated that forecasting accuracy results presented for subcases "a" to "f" are obtained through replacing the relevant new training pairs related to each case conditions in the training set with the base case data.

As it can be seen in Table III, the ANN method outperforms the linear model in both days, while the combined Linear-ANN model gives the best predictions among the benchmark models.

The reported error measures indicate that the performance of the WT-ANN approach is superior with respect to the benchmark methods. Thus, it can be stated that data decomposition significantly enhances the prediction accuracy of the ANN model. It should be noted that the data decomposition enables forecasting each decomposed level with different model specifications depending on the characteristics of the data. For instance, it has been seen from the simulation studies that WT helps to predict the high up and down ramps in the load demand by removing them from the original signal and predicting the decomposed time series separately with different ANN parameters. Thus, an improved performance is accomplished, especially for the approximation component that constitutes the largest part of the load characteristics.

Compared to the approximation level, the forecasting accuracy of three detail levels is relatively lower due to the high frequency of these components that represent the sudden changes in residential load demands. Nevertheless, the aggregation of the forecasts of all the levels results in improved accuracy since the magnitude of the detail levels and, thereof, the errors obtained for these components are too small to affect the amount of total load forecasts. Relatively to the NRMSE value of linear, ANN, and Linear-ANN models, the WT-ANN approach provides an average reduction of $60.15 \%, 48.01 \%$, and $44.46 \%$ for all cases, respectively.

Note that the improvements in the predictions of the WTANN model also stem from the benefits of optimum information and data decomposition. In order to investigate the effectiveness
TABLE III

Comparison of AVERAge ERror MEASURES of DifFERENT APPROACHES FOR DIFFERENT CASES FOR TWO REPRESENTATIVE DAYS

\begin{tabular}{|c|c|c|c|c|c|}
\hline Model & Case & Day & MAE [kW] & RMSE [kW] & NRMSE [\%] \\
\hline \multirow[t]{14}{*}{ Linear model } & \multirow[t]{2}{*}{ Base } & April 10 & 1.3278 & 1.7928 & 25.02 \\
\hline & & July 4 & 1.3224 & 1.7611 & 27.02 \\
\hline & \multirow[t]{2}{*}{$\mathrm{a}$} & April 10 & 1.3405 & 1.7959 & 25.18 \\
\hline & & July 4 & 1.3334 & 1.7494 & 27.34 \\
\hline & \multirow[t]{2}{*}{$\mathrm{b}$} & April 10 & 1.3368 & 1.7953 & 25.18 \\
\hline & & July 4 & 1.3300 & 1.7486 & 27.32 \\
\hline & \multirow[t]{2}{*}{$\mathrm{c}$} & April 10 & 1.3366 & 1.7953 & 25.18 \\
\hline & & July 4 & 1.3302 & 1.7486 & 27.32 \\
\hline & \multirow[t]{2}{*}{$\mathrm{d}$} & April 10 & 1.3790 & 1.8064 & 25.33 \\
\hline & & July 4 & 1.3765 & 1.7629 & 27.55 \\
\hline & \multirow[t]{2}{*}{ e } & April 10 & 1.3772 & 1.8058 & 25.32 \\
\hline & & July 4 & 1.3750 & 1.7623 & 27.54 \\
\hline & \multirow[t]{2}{*}{ f } & April 10 & 1.3761 & 1.8054 & 25.32 \\
\hline & & July 4 & 1.3743 & 1.7620 & 27.53 \\
\hline \multirow[t]{14}{*}{ ANN model } & \multirow[t]{2}{*}{ Base } & April 10 & 0.7876 & 1.1623 & 16.22 \\
\hline & & July 4 & 0.7585 & 1.1341 & 17.42 \\
\hline & \multirow[t]{2}{*}{$\mathrm{a}$} & April 10 & 0.9934 & 1.2719 & 18.05 \\
\hline & & July 4 & 0.9961 & 1.2736 & 19.95 \\
\hline & \multirow[t]{2}{*}{$\mathrm{b}$} & April 10 & 0.9928 & 1.2963 & 18.43 \\
\hline & & July 4 & 1.0707 & 1.4086 & 22.15 \\
\hline & \multirow[t]{2}{*}{$\mathrm{c}$} & April 10 & 0.9623 & 1.2866 & 18.28 \\
\hline & & July 4 & 1.1016 & 1.4143 & 22.30 \\
\hline & \multirow[t]{2}{*}{$\mathrm{d}$} & April 10 & 1.1271 & 1.4514 & 20.69 \\
\hline & & July 4 & 1.0277 & 1.2929 & 20.38 \\
\hline & \multirow[t]{2}{*}{$\mathrm{e}$} & April 10 & 1.0588 & 1.3842 & 19.69 \\
\hline & & July 4 & 1.0333 & 1.3167 & 20.77 \\
\hline & \multirow[t]{2}{*}{ f } & April 10 & 1.3219 & 1.4042 & 20.03 \\
\hline & & July 4 & 1.0660 & 1.3684 & 21.57 \\
\hline \multirow[t]{14}{*}{ Linear-ANN model } & \multirow[t]{2}{*}{ Base } & April 10 & 0.7782 & 1.1462 & 15.99 \\
\hline & & July 4 & 0.7517 & 1.1211 & 17.21 \\
\hline & $\mathrm{a}$ & April 10 & 0.8280 & 1.1882 & 16.66 \\
\hline & & July 4 & 0.8291 & 1.2273 & 19.18 \\
\hline & $\mathrm{b}$ & April 10 & 0.8441 & 1.1906 & 16.84 \\
\hline & & July 4 & 0.8489 & 1.2795 & 20.11 \\
\hline & $\mathrm{c}$ & April 10 & 0.9410 & 1.2813 & 18.22 \\
\hline & & July 4 & 0.8430 & 1.2359 & 19.33 \\
\hline & $\mathrm{d}$ & April 10 & 0.9343 & 1.3599 & 19.26 \\
\hline & & July 4 & 0.9293 & 1.2447 & 19.58 \\
\hline & $\mathrm{e}$ & April 10 & 0.9832 & 1.3400 & 19.13 \\
\hline & & July 4 & 0.9248 & 1.2478 & 19.64 \\
\hline & $\mathrm{f}$ & April 10 & 1.1893 & 1.3628 & 19.41 \\
\hline & & July 4 & 1.1250 & 1.2751 & 20.07 \\
\hline Proposed model & Base & April 10 & 0.3994 & 0.6419 & 8.96 \\
\hline & & July 4 & 0.3588 & 0.6158 & 9.47 \\
\hline & $\mathrm{a}$ & April 10 & 0.4903 & 0.6657 & 9.35 \\
\hline & & July 4 & 0.4697 & 0.6250 & 9.88 \\
\hline & $\mathrm{b}$ & April 10 & 0.5575 & 0.7291 & 10.92 \\
\hline & & July 4 & 0.4942 & 0.6296 & 9.92 \\
\hline & $\mathrm{c}$ & April 10 & 0.6721 & 0.8426 & 12.09 \\
\hline & & July 4 & 0.5704 & 0.7768 & 12.40 \\
\hline & $\mathrm{d}$ & April 10 & 0.5469 & 0.7041 & 9.94 \\
\hline & & July 4 & 0.4692 & 0.6229 & 9.76 \\
\hline & $\mathrm{e}$ & April 10 & 0.6158 & 0.7445 & 10.58 \\
\hline & & July 4 & 0.4959 & 0.6350 & 9.93 \\
\hline & $\mathrm{f}$ & April 10 & 0.6186 & 0.7756 & 11.08 \\
\hline & & July 4 & 0.4807 & 0.6374 & 10.11 \\
\hline
\end{tabular}

of the proposed approach over a much larger dataset, forecasts are also carried out for 30 random days and the error metrics calculated are listed in Table IV. Similar to the results given in Table III, the WT-ANN method clearly outperforms the benchmark methods, a fact that further confirms the contribution of the ideas presented in this paper to improving the accuracy of residential demand forecasting. 
TABLE IV

Comparison of Average ERror Measures of DifFERENT Approaches FOR DIFFERENT CASES FOR 30 RANDOM DAYS

\begin{tabular}{|c|c|c|c|c|}
\hline Model & Case & MAE [kW] & RMSE [kW] & NRMSE [\%] \\
\hline \multirow[t]{7}{*}{ Linear model } & Base & 1.3880 & 1.8992 & 28.58 \\
\hline & $\mathrm{a}$ & 1.3150 & 1.8155 & 28.53 \\
\hline & $\mathrm{b}$ & 1.4092 & 1.9238 & 28.64 \\
\hline & $\mathrm{c}$ & 1.4494 & 1.9623 & 28.71 \\
\hline & $\mathrm{d}$ & 1.3932 & 1.8725 & 30.61 \\
\hline & $\mathrm{e}$ & 1.4717 & 1.9641 & 30.36 \\
\hline & $\mathrm{f}$ & 1.5184 & 2.0074 & 30.18 \\
\hline \multirow[t]{7}{*}{ ANN model } & Base & 0.9185 & 1.1271 & 17.08 \\
\hline & $\mathrm{a}$ & 0.9245 & 1.1242 & 17.88 \\
\hline & $\mathrm{b}$ & 0.9376 & 1.1594 & 17.32 \\
\hline & $\mathrm{c}$ & 0.9705 & 1.1948 & 17.53 \\
\hline & $\mathrm{d}$ & 0.9191 & 1.1100 & 18.40 \\
\hline & $\mathrm{e}$ & 0.9690 & 1.1980 & 18.52 \\
\hline & $\mathrm{f}$ & 0.9996 & 1.2326 & 18.48 \\
\hline \multirow[t]{7}{*}{ Linear-ANN model } & Base & 0.8680 & 1.0903 & 16.55 \\
\hline & $\mathrm{a}$ & 0.8712 & 1.0857 & 17.26 \\
\hline & $\mathrm{b}$ & 0.8879 & 1.1230 & 16.81 \\
\hline & $\mathrm{c}$ & 0.9222 & 1.1592 & 17.03 \\
\hline & $\mathrm{d}$ & 0.8688 & 1.0726 & 17.76 \\
\hline & $\mathrm{e}$ & 0.9215 & 1.1624 & 18.12 \\
\hline & $\mathrm{f}$ & 0.9535 & 1.1977 & 18.04 \\
\hline \multirow[t]{7}{*}{ Proposed model } & Base & 0.5361 & 0.6522 & 9.90 \\
\hline & $\mathrm{a}$ & 0.5391 & 0.6508 & 10.35 \\
\hline & $\mathrm{b}$ & 0.5457 & 0.6683 & 10.00 \\
\hline & $\mathrm{c}$ & 0.5621 & 0.6861 & 10.08 \\
\hline & $\mathrm{d}$ & 0.5364 & 0.6436 & 10.66 \\
\hline & $\mathrm{e}$ & 0.5614 & 0.6876 & 10.72 \\
\hline & $\mathrm{f}$ & 0.5767 & 0.7049 & 10.62 \\
\hline
\end{tabular}

Regarding the runtime efficiency of the proposed model, it can be roughly said that the computational time of the WT-ANN method is relatively higher than the benchmark methods, since including a data decomposition method generally improves forecasts at the expense of increasing the runtime. In order to decrease the runtime of the WT-ANN model, as mentioned before, one-time training and data selection are used in the study. These two features facilitate and considerably speed up the training phase without causing any accuracy decrease in the test set. Thanks to the mentioned advantages of the proposed method, a reasonable computational time compared to the average time of the other short-term forecasting models in the literature, which is about $14 \mathrm{~s}$ in the MATLAB environment on a standard computer, has been achieved for 24-h-ahead forecasts.

\section{CONCLUSION}

In this study, a combined WT-ANN-based load forecasting strategy to provide assessment of DR-driven load pattern elasticity of smart households was proposed.

The presented approach is new compared to other load forecasting approaches using historical data to forecast hour or dayahead variations, as the employed methodology considered daily data as a whole package and was capable of providing forecasts for any future data instead of just steps ahead. Moreover, consideration of the impacts of pricing-based DR on load pattern variation of smart end-user premises is a new contribution to the literature and can be extended as a new tool for system operators to analyze the results of their DR strategies during planning phase, in order to decide if further revisions or actions are required.

The performance of the proposed methodology was compared with different approaches and the superiority of the developed structure was demonstrated through performance metrics. The uncertainty in the end-users' behavior and the development of appropriate methods in order to handle it will be the direction of future studies to be pursued by the authors.

\section{REFERENCES}

[1] K. H. S. V. S. Nunna and S. Doolla, "Responsive end-user-based demand side management in multimicrogrid environment," IEEE Trans. Ind. Informat., vol. 10, no. 2, pp. 1262-1272, May 2014.

[2] V. C. Gungor et al., "A survey on smart grid potential applications and communication requirements," IEEE Trans. Ind. Informat., vol. 9, no. 1, pp. 28-42, Feb. 2013.

[3] A. Safdarian, M. F. Firuzabad, and M. Lehtonen, "A distributed algorithm for managing demand response in smart grids," IEEE Trans. Ind. Informat., vol. 10, no. 4, pp. 2385-2393, Nov. 2014.

[4] O. Kilkki, A. Alahaivala, and I. Seilonen, "Optimized control of pricebased demand response with electric storage space heating," IEEE Trans. Ind. Informat., vol. 11, no. 1, pp. 281-288, Feb. 2015.

[5] K. J. Chua, S. K. Chou, W. M. Yang, and J. Yan, "Achieving better energy efficient air conditioning-A review of technologies and strategies," Appl. Energy, vol. 104, pp. 87-104, Apr. 2013.

[6] F. de Angelis, M. Boaro, S. Squartini, F. Piazza, and Q. Wei, "Optimal home energy management under dynamic electrical and thermal constraints," IEEE Trans. Ind. Informat., vol. 9, no. 3, pp. 1518-1527, Aug. 2013.

[7] S. Harkin, "Home energy management in Europe, lots of solutions, but what's the problem," Delta Energy Environment, Aug. 2011.

[8] B. Asare-Bediako, W. L. Kling, and P. F. Ribeiro, "Home energy management systems: Evolution, trends and frameworks," in Proc. 47th Int. Univ. Power Eng. Conf., Sep. 2012, pp. 1-5.

[9] A smart electricity rate from Ameren Illinois. [Online]. Available: http://www.powersmartpricing.org/

[10] D. S. Kirchen and G. Strbac, Fundamentals of Power System Economics. Hoboken, NJ, USA: Wiley, 2004.

[11] D. S. Kirchen, G. Strbac, P. Cumperayot, and D. P Mendes, "Factoring the elasticity of demand in electricity prices," IEEE Trans. Power Syst., vol. 15, no. 2, pp. 612-617, May 2000.

[12] C. E. Borges, Y. K. Penya, and I. Fernandez, "Evaluating combined load forecasting in large power systems and smart grids," IEEE Trans. Ind. Informat., vol. 9, no. 3, pp. 1570-1577, Aug. 2013.

[13] Y. Ozturk, D. Senthilkumar, S. Kumar, and G. Lee, "An intelligent home energy management system to improve demand response," IEEE Trans. Smart Grid, vol. 4, no. 2, pp. 694-701, Jun. 2013.

[14] J. Byun, I. Hong, B. Kang, and S. Park, "A smart energy distribution and management system for renewable energy distribution and contextaware services based on user patterns and load forecasting," IEEE Trans. Consum. Electron., vol. 57, no. 2, pp. 436-444, May 2011.

[15] M. Chaouch, "Clustering-based improvement of nonparametric functional time series forecasting: Application to intra-day household-level load curves," IEEE Trans. Smart Grid, vol. 5, no. 1, pp. 411-419, Jan. 2014.

[16] R. P. Behnke et al., "A microgird energy management system based on the rolling horizon strategy," IEEE Trans. Smart Grid, vol. 4, no. 2, pp. 996-1006, Jun. 2013.

[17] L. Ghelardoni, A. Ghio, and D. Anguita, "Energy load forecasting using empirical mode decomposition and support vector regression," IEEE Trans. Smart Grid, vol. 4, no. 1, pp. 549-556, Mar. 2013.

[18] L. Hernandez et al., "A survey on electric power demand forecasting: Future trends in smart grids, microgrids and smart buildings," IEEE Commun. Surveys Tuts., vol. 16, no. 3, pp. 1460-1495, Jul. 2014.

[19] M. Kohansal and H. Mohsenian-Rad, "A closer look at demand bids in California ISO energy market," IEEE Trans. Power Syst., vol. 31, no. 4, pp. 3330-3331, Jul. 2016.

[20] Q. Zhou, W. Guan, and W. Sun, "Impact of demand response contracts on load forecasting in a smart grid environment," presented at the IEEE Power Energy Society General Meeting, San Diego, CA, USA, Jul. 2012. 
[21] M. Kohansal and H. Mohsenian-Rad, "Extended-time demand bids: A new bidding framework to accommodate time-shiftable loads," presented at the IEEE Power Energy Society General Meeting, Denver, CO, USA, Jul. 2015.

[22] O. Erdinc, N. G. Paterakis, T. D. P Mendes, A. G. Bakirtzis, and J. P. S. Catalão, "Smart household operation considering bi-directional EV and ESS utilization by real-time pricing-based DR,' IEEE Trans. Smart Grid, vol. 6, no. 3, pp. 1281-1291, May 2015.

[23] A. Tascikaraoglu and M. Uzunoglu, "A review of combined approaches for prediction of short-term wind speed and power," Renewable Sustain. Energy Rev., vol. 34, pp. 243-254, Jun. 2014.

[24] A. Tascikaraoglu, A. R. Boynuegri, and M. Uzunoglu, "A demand side management strategy based on forecasting of residential renewable sources: A smart home system in Turkey," Energy Buildings, vol. 80, pp. 309-320, Sep. 2014.

[25] ComEd residential real-time pricing program. [Online]. Available: http://rrtp.comed.com

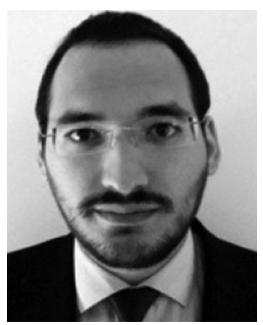

Nikolaos G. Paterakis (S'14-M'15) received the Dipl.Eng. degree from the Department of Electrical and Computer Engineering, Aristotle University of Thessaloniki, Thessaloniki, Greece, in 2013, and the Ph.D. degree from the University of Beira Interior, Covilhã, Portugal, in 2015, working under the EU FP7 funded Project "SiNGULAR."

Since October 2015, he has been a Postdoctoral Fellow at the Department of Electrical Engineering, Eindhoven University of Technology, Eindhoven, the Netherlands. His research interests include power systems operation and planning, renewable energy integration, ancillary services, demand response, and smart grid applications.

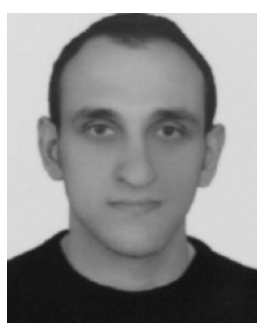

Akın Taşcıkaraoğlu (S'12-M'14) received the B.Sc., M.Sc., and Ph.D. degrees from Yildiz Technical University, Istanbul, Turkey, in 2006, 2008, and 2013, respectively.

Since February 2012, he has been a Researcher in the Department of Electrical Engineering, Yildiz Technical University, Istanbul. From 2013 to 2014, he was a Postdoctoral Scholar at the University of California, Berkeley, CA, USA. His research interests include among others forecasting, renewable energy, power system operation, smart grid, and demand response.

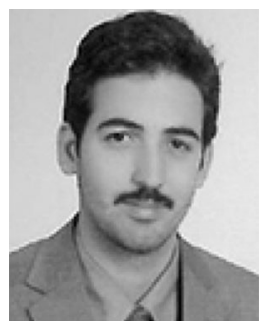

Ozan Erdinc (M'14-SM'16) received the B.Sc. M.Sc., and Ph.D. degrees from Yildiz Technical University, Istanbul, Turkey, in 2007, 2009, and 2012, respectively.

Until May 2013, he worked in private sector in different positions including Electrical Installations, Renewable Energy Investments, and Procurement Expert. He has been a Postdoctoral Fellow at the University of Beira Interior, Covilhã, Portugal, since May 2013, under the EU FP7 funded Project "Smart and Sustainable Insular Electricity Grids Under Large-Scale Renewable Integration." From February 2014 to January 2015, he was an Assistant Professor with the Department of Electrical-Electronics Engineering, Istanbul Arel University, Istanbul. In January 2015, he joined the Department of Electrical Engineering, Yildiz Technical University, Istanbul, where he is currently an Associate Professor. He is currently also a Researcher with the INESC-ID, Lisbon. His research interests include hybrid renewable energy systems, electric vehicles, power system operation, and smart grid technologies.

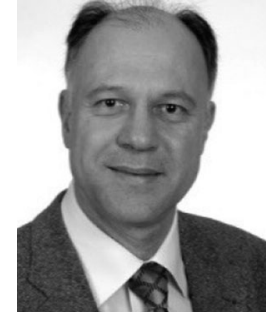

Anastasios G. Bakirtzis (S'77-M'79-SM'95F'15) received the Dipl.Eng. degree from the Department of Electrical Engineering, National Technical University, Athens, Greece, in 1979 and the M.S.E.E. and Ph.D. degrees from the Georgia Institute of Technology, Atlanta, GA USA, in 1981 and 1984, respectively.

Since 1986 he has been with the Electrical Engineering Department, Aristotle University of Thessaloniki, Thessaloniki, Greece, where he is currently a Professor. His research interests include power system operation, planning, and economics.

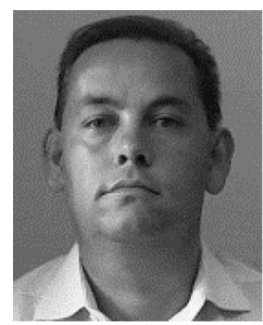

João P. S. Catalão (M'04-SM'12) received the M.Sc. degree from the Instituto Superior Técnico, Lisbon, Portugal, in 2003, and the Ph.D. degree and Habilitation for Full Professor ("Agregação") from the University of Beira Interior (UBI), Covilha, Portugal, in 2007 and 2013, respectively.

$\mathrm{He}$ is currently a Professor at the Faculty of Engineering, the University of Porto, Porto, Portugal, and a Researcher at INESC TEC, INESCID/IST-UL, and C-MAST/UBI. He was the Primary Coordinator of the EU-funded FP7 project "Smart and Sustainable Insular Electricity Grids Under Large-Scale Renewable Integration," a 5.2-million-euro project involving 11 industry partners. He has authored or coauthored more than 450 publications, including 147 journal papers, 271 conference proceedings papers, 23 book chapters, and 11 technical reports, with an $h$-index of 27 (according to Google Scholar), having supervised more than 40 Postdoctoral, Ph.D., and M.Sc. students. He is the Editor of the books entitled Electric Power Systems: Advanced Forecasting Techniques and Optimal Generation Scheduling and Smart and Sustainable Power Systems: Operations, Planning and Economics of Insular Electricity Grids (CRC Press, 2012 and 2015, respectively). His research interests include power system operations and planning, hydro and thermal scheduling, wind and price forecasting, distributed renewable generation, demand response, and smart grids.

Prof. Catalão is an Editor of the IEEE TRANSACTIONS ON SMART GRID, an Editor of the IEEE TRANSACTIONS ON SUSTAINABLE ENERGY, and an Associate Editor of the IET Renewable Power Generation. He was the Guest Editor-in-Chief for the Special Section on "Real-Time Demand Response" of the IEEE TRANSACTIONS ON SMART GRID, published in December 2012, and the Guest Editor-in-Chief for the Special Section on "Reserve and Flexibility for Handling Variability and Uncertainty of Renewable Generation" of the IEEE TRANSACTIONS ON SUSTAINABLE ENERGY, published in April 2016. He received the 2011 Scientific Merit Award UBI-FE/Santander Universities and the 2012 Scientific Award UTL/Santander Totta. He has also received four Best Paper Awards at IEEE Conferences. 